\title{
SURVEILLANCE OF AEDES AEGYPTI AFTER RESURGENCE IN DOWNTOWN ST. AUGUSTINE, NORTHEASTERN FLORIDA
}

\author{
DANIEL DIXON ${ }^{1,2}$, DENA AUTRY ${ }^{2}$, JAMES MARTIN³, AND RUI-DE XUE² \\ 'Current Address: United States Department of Agriculture, Agricultural \\ Research Services, 1700 SW 23 ${ }^{\text {rd }}$ Dr, Gainesville, FL 32608
}

\author{
${ }^{2}$ Anastasia Mosquito Control District, 120 EOC Drive, St. Augustine, FL 32092
${ }^{3}$ Quantitative Disease Ecology \& Conservation Lab, Department of Geography, University of Florida, Gainesville, FL, 32611

\section{Subiect Editor: Derrick Mathias}

\begin{abstract}
Aedes aegypti is an anthropophilic vector of several arboviruses, including yellow fever, Dengue virus, Chikungunya virus, and the infamous Zika virus. In 2016, Zika virus was spreading rapidly throughout Brazil and mosquito control districts expected Zika virus would be imported to Florida and vectored by endemic Aedes aegypti. Aedes aegypti often takes advantage of cryptic oviposition sites and therefore circumvents conventional control and surveillance strategies used by mosquito control practitioners. The objective of this study was to find Ae. aegypti breeding sites in the tourist district of Saint Augustine, FL, using a door-to-door on-foot approach. Mosquito control technicians, biologists and interns worked to inspect and treat each property for Ae. aegypti. Additionally, residents were informed about Ae. aegypti and its public health risk factors. In total, Anastasia Mosquito Control District inspected 1199 of the 1995 parcels in downtown Saint Augustine (60\% coverage) in three months. Artificial containers were found at 1,099 of the homes inspected, and Ae. aegypti were found at 120 homes in the area. Each property where mosquito larvae and/or adults were detected was treated using source reduction, larvicides and adulticides. Residents were educated about this project and Ae. aegypti via small flyers, door hangers, pamphlets and/or verbal communication. This study provided insight into the location of Ae. aegypti breeding sites in the tourist district of Saint Augustine, FL, which will facilitate future control efforts.
\end{abstract}

Key Words: Aedes aegypti, surveillance, trap, habitat, dengue vector

\section{INTRODUCTION}

Aedes aegypti (L.) efficiently vectors a number of arboviruses, including Zika virus, yellow fever virus, dengue virus, and chikungunya virus, each of which may cause severe morbidity, lifelong health complications and sometimes death (Braak et al. 2018). However, Zika virus became a notable global health concern in 2016 because of its association with Guillain-Barre syndrome, rare cases of meningoencephalitis, and birth defects including microcephaly and eye issues (blindness, optic neuritis, and intraretinal hemorrhages) (Koppolu and Raju, 2018). In addition, Zika virus is sexually transmitted and can persist in sperm for the first few weeks or up to six months post-infection (Mead et al. 2018). Finally, there is still no vaccine or antiviral treatment for Zika virus, leaving little to no medical preventative practices and only vector control to contain its spread (Poland et al. 2019). In 2015, there were 62 symptomatic Zika virus disease cases in the United States and 10 symptomatic cases in U.S. territories (CDC, 2019). In 2016, the Zika virus caseload increased to 5,168 symptomatic U.S. cases and 36,512 symptomatic cases among U.S. territories (ibid). With the combination of a large spike in Zika virus transmission and no available vaccine or antiviral treatment, preventing an outbreak through vector control and public outreach became a major goal of the mosquito control district in Saint Johns County, FL.

Despite the urgency to control Ae. aegypti and prevent the emergence of Zika virus in Saint Augustine, little information was avail- 
able on vector density and oviposition-site locations for targeted treatment of the area. Aedes aegypti oviposits in artificial containers such as bird baths, bottles, paint buckets, discarded tires, and even bottle caps (CDC, 2017). Along with artificial containers, bromeliads were recently identified as both a harborage and oviposition site for Ae. aegypti (Wilke et al. 2018; Wilke et al 2019). Peri-domestic mosquitoes rest underneath bromeliad leaf axils to prevent dehydration in the heat (Muzari et al. 2014), feed from bromeliad flowers and extrafloral nectaries (Xue et al. 2018), and oviposit in the water collected between bromeliad leaf axils (Pittendrigh, 1948; O'Meara et al. 2003; Mocellin et al. 2009; Xue et al. 2018). Along with bromeliads, container-inhabiting mosquitoes are also found in man-made structures, such as wells (Russel et al. 1992), rain barrels (Christophers, 1960), roof gutters (Montgomery and Ritchie, 2002), and construction sites (Liang et al. 2018).

Aedes aegypti has a dynamic history in Saint Johns County that was heavily driven by the invasion of Aedes albopictus (Skuse). Aedes aegypti was detected in Saint Augustine and most of Florida around the early 1900s when dengue fever outbreaks were occurring throughout the state (Rey, 2014). Aedes albopictus was first detected in discarded tires in northeast Florida (Duval County) around 1986 (O'meara et al. 1995) and began displacing Ae. aegypti in Saint Johns County when it invaded the area in 1989 (ibid). By 1994, Ae. albopictus was found throughout much of Florida and displaced Ae. aegypti in many locations (ibid). This pattern of $A e$. albopictus displacement of Ae. aegypti also occurred in other regions within the United States and elsewhere (Lounibos, 2007; Kaplan et al. 2010; Lounibos and Kramer, 2016). In 2016, Ae. aegypti was detected in Saint Augustine after 12 years of absence while dipping larvae from a tire near a busy tourist site, which prompted an increase in Ae. aegypti surveillance in the area so that targeted treatments based on mosquito location could be implemented.

In Saint Augustine, FL, the Anastasia Mosquito Control District (AMCD) is still devel- oping a program focused on the surveillance and control of Ae. aegypti, which is especially important because Saint Augustine attracts numerous international tourists. In 2016, AMCD first started its door-to-door mosquito surveillance and control campaign with the goal of eradicating Ae. aegyptifrom major tourist areas. A similar campaign was tried in Brazil in the early 1930s. There the strategies for eradication were to identify areas that favored the spread of yellow fever (e.g., areas infested with Ae. aegypti) and survey the human population through testing and autopsies (Löwy, 2017). During this campaign, weekly inspections were made at Aedes-infested areas with fines for non-compliant residents (ibid). Mosquito inspectors were heavily supervised, which was key to the success of the program (ibid), and in the 1940s, Ae. aegypti was deemed "eradicated" in Brazil. However, Ae. aegypti control efforts were not standardized throughout the Americas (Kotsakiozki et al. 2017; Löwy, 2017), and these non-uniform standards allowed Ae. aegypti to re-invade Brazil from nearby countries like Venezuela and the United States (ibid). The 2016 eradication efforts by the Anastasia Mosquito Control District involved the identification of Aedes habitats, inspection, and treatment of the area one day per week for 3-4 hours. However, the eradication period was limited to just three months, confined to just the downtown area, and little information was collected about Aedes oviposition and resting sites. In 2016, Ae. aegypti was detected in only six locations in downtown Saint Augustine, whereas Ae. albopictus and Culex quinquefasciatus Say were detected throughout the rest of the downtown area.

Biological larvicides are often used in an integrated mosquito management program to limit the application of adulticides. However, controlling Ae. aegypti has proven to be difficult due to their propensity to oviposit in a variety of cryptic breeding sites, as well as their egg resilience, insecticide resistance, and their close association with humans (Reiter, 2007; Viennet et al. 2016). Due to these challenges, improvements are needed to effectively control Ae. aegypti with integrated pest management practices. In 2017, AMCD 
continued the door-to-door Ae. aegypti control campaign begun in 2016, but with the goal of implementing higher resolution surveillance of Ae. aegypti compared to the 2016 efforts by inspecting every property, business, and street in the downtown Saint Augustine area.

This article focuses only on the surveillance improvements for the 2017 Ae. aegypti eradication campaign in Saint Augustine. Surveillance was conducted through individual parcel inspections on foot, going through the back and front of each property, business, or abandoned lot to search for larval and adult Ae. aegypti. Data were collected from each inspected parcel in the downtown area concerning container density, larval and adult mosquito presence, and human housing characteristics (air conditioning and screened windows/entrances). These data were used to map locations that could potentially act as $A e$. aegypti habitat and therefore glean information on new and existing areas where control efforts could be better focused, making control of $A e$. aegypti more efficient. Close attention was paid to areas that had Ae. aegypti larvae and/or adults to identify potential hot-spot areas for future container management and insecticide application. Efforts were made to control the population while conducting surveillance during the 2017 campaign, but no data are provided on the success or failure of control practices.

\section{MATERIALS AND METHODS}

Data concerning 1,995 parcels was gathered from the Saint John's County Appraiser's Office, and addresses were collated into excel sheets for teams to refer to in the field. The following information about each parcel was collected by field teams: Number of containers, presence of larvae and adults and number of bromeliads. Additionally, the presence of barriers (screened windows/ doors and air conditioning) to the inside of homes and businesses was documented because they are recommended by the CDC to prevent blood feeding activity from $A e$. aegypti (CDC, 2019). The spatial distribu- tion of containers was analyzed using a map produced on ARC-GIS (Redlands, CA). The surveillance study was conducted for a total of three months from May to August in 2017. Each parcel was examined for 5 - 10 minutes depending on the size of the property and time needed for larval source reduction and insecticide application. Adult mosquitoes were treated with DUET® diluted $50 \%$ with Orchex oil (Clarke ${ }^{\circledR}$, St. Charles, IL) using a Longray Handheld Pioneer ULV fogger (PestGoAway®, Hayward, CA). Artificial containers were treated with Natular ${ }^{\circledR}$ DT tablets (Clarke, St. Charles, IL) and Sustain MBG (AllPro®, Northville, MI) according to the specifications on the insecticide labels. Team investigations and treatments of parcels were only done once with no return inspections, which was due to the large number of parcels and limited personnel for inspections and treatments. Each team was supplied with a backpack to hold all supplies and PPE and included: Pasteur pipets and turkey basters for larval collections from artificial containers, whirl packs for transporting a minimum of 10 live larvae from positive parcels back to the laboratory for analysis, markers and pens to record data into log sheets for each parcel, and binders for holding the data sheets for each team. Collected larvae were brought back to the lab, separated by address, and identified to species after adult emergence on a lab bench at room temperature and/or in an insectary at $28^{\circ} \mathrm{C}$ and $80 \%$ relative humidity. Residents were educated throughout the program about Ae. aegypti and Zika virus from Mosquito control experts and the local Department of health using door-hangers, pamphlets, and in-person conversation.

\section{RESULTS}

From May through August 2017, field teams inspected 1,199 out of the 1,995 parcels assigned to them, which was a $60 \%$ coverage of the downtown Saint Augustine area. Some inspections were more exhaustive than others due to access limitations at some properties. For breeding site inspections, a container was defined as any object visible 
to technicians that could hold at least 2.5 mLs (or one bottlecap) of water. Field teams found containers on $91 \%(1,088)$ of the parcels that were inspected (Table 1). Container density and location was mapped using ARCGIS to determine the distribution of homes that are likely breeding sites for Aedes aegypti (Figure 1). Bromeliads were also detected in downtown Saint Augustine. Specifically, 11\% (132) of the parcels investigated had at least 1 bromeliad, and $54 \%$ (71) of the bromeliadpositive sites had more than 10 per parcel. If more than 10 containers and/or bromeliads were found at a parcel, it was considered a major potential breeding site for Ae. aegypti. Larvae were detected at $19.5 \%$ (235) of the parcels that were inspected. These were collected and raised to adulthood for species identification. Only a portion of the larvae collected were identified due to limitations in employees and resources. For a sample of 154 larval positive parcels, Aedes aegypti was identified at $78 \%$ (120) of them and their locations were tracked on Google maps ${ }^{\circledR}$ (Google, San Francisco, CA) (Figure 2).

The presence/absence of barriers (screened windows/doors and air conditioning) to the inside of homes and businesses was also documented because they are recommended from the CDC to prevent feeding activity from Aedes aegypti (CDC, 2019). Screened windows/doors were found at $48.8 \%$ (585) of the inspected parcels and air conditioning was found at $86.9 \%(1,042)$.

\section{DISCUSSION}

In the summer of 2017, Anastasia Mosquito Control District field teams inspected

Table 1. Downtown Surveillance of Ae. aegypti-parameters and data

\begin{tabular}{lc}
\hline \hline Start date & May 2017 \\
End date & August 2017 \\
Total acres & 825 \\
Number of Parcels & 1995 \\
Parcels Inspected & 1199 \\
Parcels inspected with containers & 1088 \\
Parcels inspected with bromeliads & 132 \\
Parcels inspected with larvae & 235 \\
Parcels inspected with Aedes aegypti & 120 \\
\hline
\end{tabular}

approximately $60 \%$ of the parcels in downtown Saint Augustine. Container distribution based on density and location were mapped for future reference as potential $A e$. aegypti oviposition sites. Bromeliad density and location were also documented for future surveillance and larval control. Houses and buildings with barriers to prevent mosquito entry, such as screened windows/doors and air conditioning, were found on at least $48 \%$ of the parcels inspected. The majority of mosquitoes collected from downtown Saint Augustine during the surveillance period were either $C x$. quinquefasciatus or $A e$. aegypti. Ae. albopictus was not detected from door-to-door container inspections throughout the study duration.

One of the major findings from this research was the number of houses with a high density of water-holding artificial containers. Each parcel containing 10 or more containers may represent a threat to human health due to the likelihood of attracting gravid female $A e$. aegypti, although there are no universally accepted thresholds for larval indicators above which arbovirus transmission is likely to occur (CDC 2017). Nevertheless, high container density may increase the likelihood of Ae. aegypti establishment, which could lead to continued spread of this species and ultimately pathogen transmission and incidence of human disease. Importantly, parcels with a high density of containers were spread throughout the study area, with some such parcels adjacent to one other in small clusters. The latter situation is relatively easy to treat, but when target parcels are spread out, greater effort and expense are required to reach them for chemical application. Another potential breeding site for Ae. aegypti are bromeliads, which were also found throughout the downtown area. Bromeliad density varied among parcels from complete absence to low (1-8 bromeliads) or high $(>10)$ densities. Although bromeliads are eye-catching and hardy, they potentially act as harborages for Ae. aegypti and other mosquito species by providing shade, nectar through floral and extra-floral nectaries, and water collected in leaf axils, which function as oviposition sites (Wilke et al. 2018). 


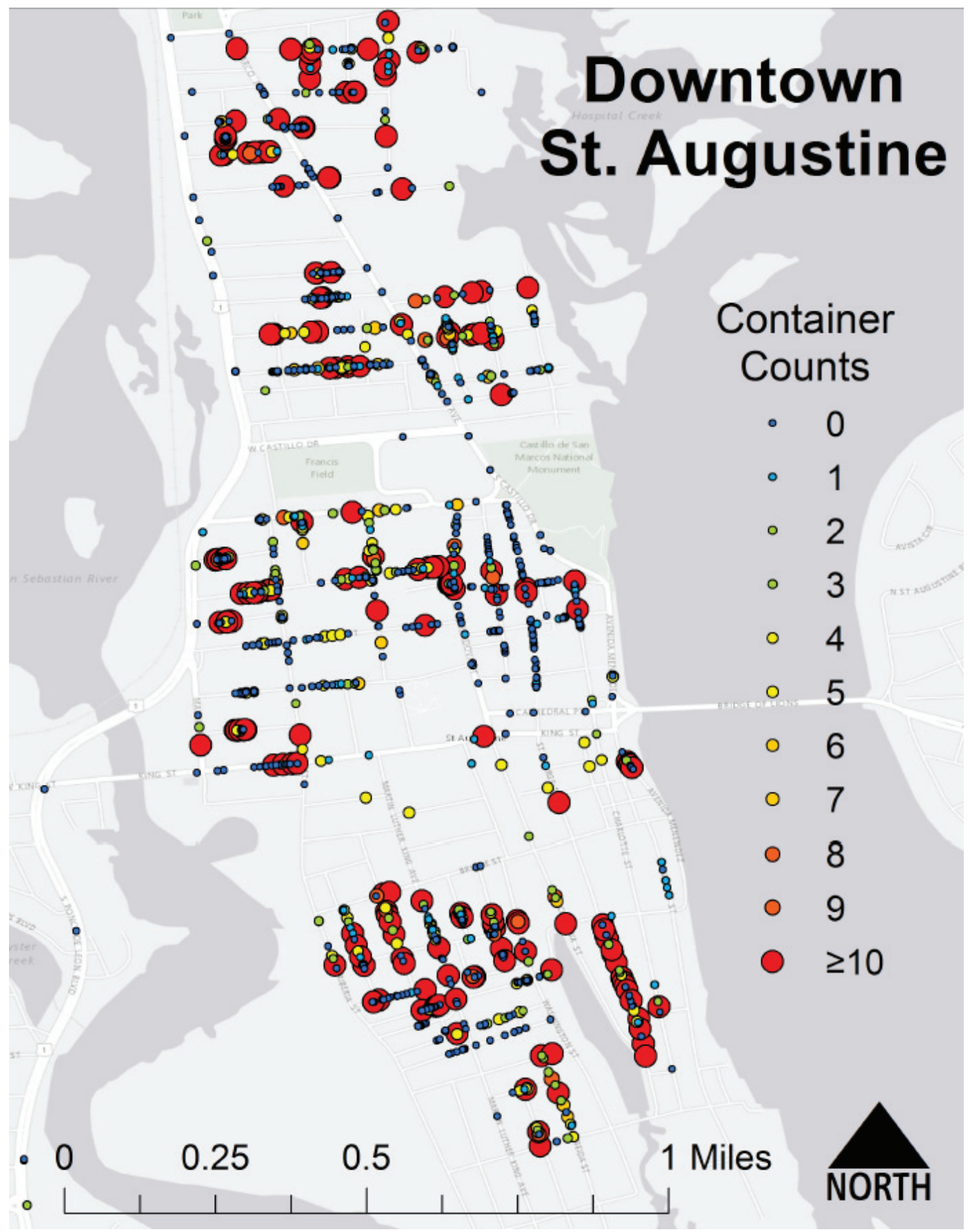

Figure 1. Container distribution in downtown Saint Augustine. The map shows the distribution of containers in the parcels inspected throughout downtown Saint Augustine. Container density varied from 0 to greater than 10, represented by circles with a gradient of color temperature and size as shown in the legend.

Regarding the latter, studies examining the use of bromeliads as breeding sites for Ae. aegypti have had conflicting results. Multiple studies in Brazil have shown that Ae. aegypti oviposit in leaf axils, but not to a degree that is biologically significant (Maciel-de-Freitas et al. 2007; Mocellin et al. 2009; Santos et al. 2011). Additionally, when bromeliads 


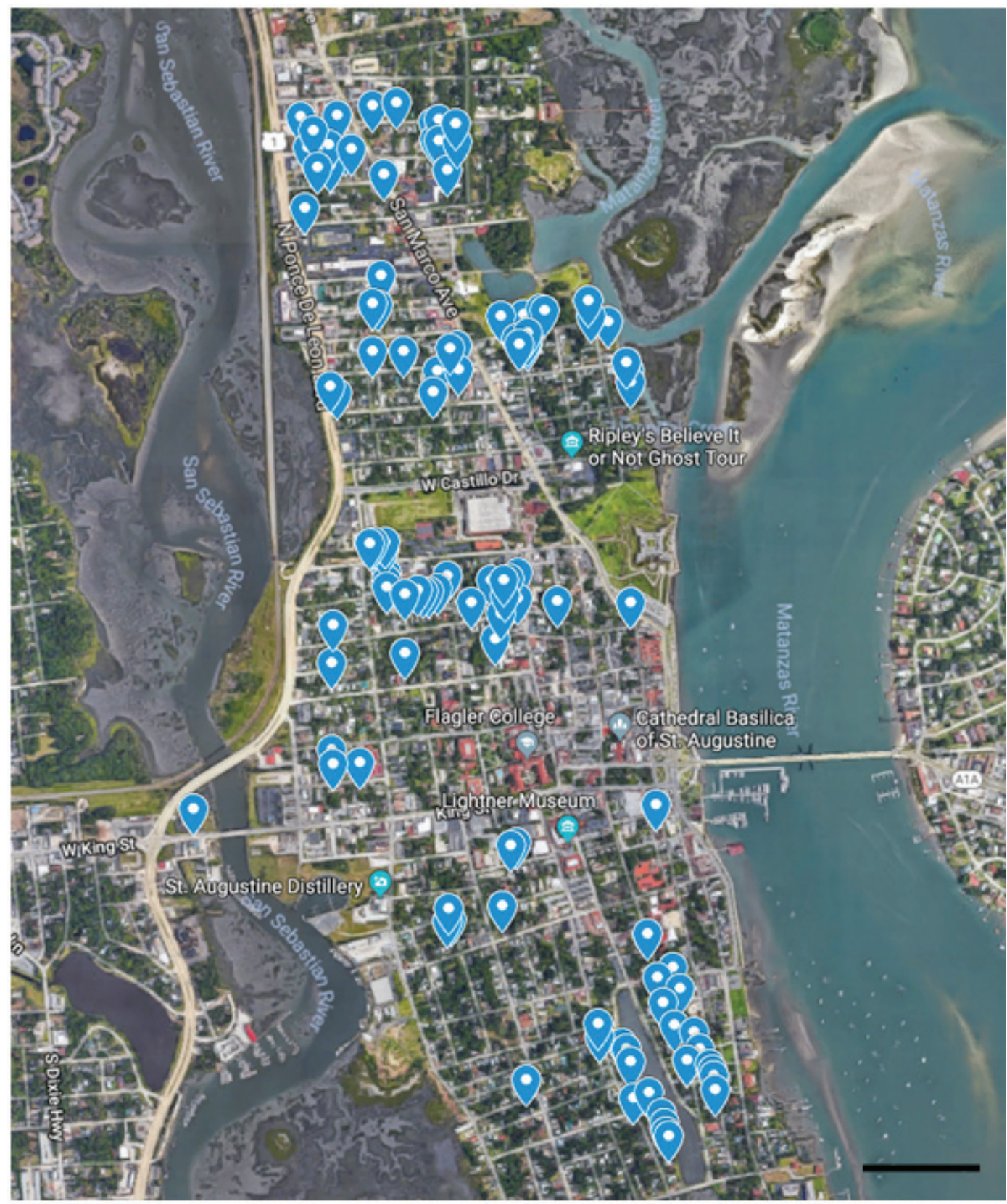

Figure 2. Distribution of Ae. aegypti in parcels inspected throughout downtown Saint Augustine. Below is a satellite image of downtown Saint Augustine with blue map pins inserted at addresses where Ae. aegypti larvae were captured. The black scale bar below is 1000 feet.

were targeted for control during dengue outbreaks, Mocellin et al. (2009) suggested that bromeliads should not be the focus of intervention strategies. However, Wilke et al. (2018) surveyed bromeliads in Miami during a Zika virus outbreak and showed that bromeliads may have led to the proliferation of $A e$. aegypti in that city. In addition, previous studies found Ae. albopictus, Ae. aegypti, and other mosquitoes that vector pathogens breeding in bromeliads from Saint Augustine (Bibbs et al. 2018; Xue et al. 2018). Considering that bromeliads in Miami and Saint Augustine act as potential oviposition sites 
for Ae. aegypti and Ae. albopictus, they warrant continued surveillance and treatment for container-inhabiting mosquitoes that could vector Zika virus to Florida residents.

One of the caveats to door-to-door surveillance strategies is the time and labor costs associated with regular inspections. Aedes mosquitoes in urban and suburban locations are elusive because they deposit eggs in hard to reach, or cryptic, oviposition sites. Examples of cryptic oviposition sites include corrugated extension spouts (Unlu et al. 2014), gutters, exposed septic tanks, storm drains, and old sprinkler heads (CDC, 2017). In order to detect these sites, field teams needed to perform a thorough search of each parcel. This area was relatively small compared to other areas throughout the county, but due to a high density of parcels (at least 2000) and limited accessibility to sections of property, the detection of all mosquito oviposition sites, especially cryptic ones, was not feasible. If Saint Augustine had been in a mosquitoborne disease epidemic, $90 \%$ of the homes would have needed to be inspected within a one-week period (CDC, 2017) to collect the surveillance data needed to contain pathogen transmission. For perspective, it took field teams in this study three months to cover $60 \%$ of the total downtown area. Thus, a door-to-door strategy may be more effective in isolated areas with a smaller concentration of homes where time can be given for thorough inspections of each parcel.

AMCD personnel also faced multiple challenges when trying to perform door-todoor inspections. Weather events, like massive rain or extreme heat, prevented field teams from inspecting homes for multiple days throughout the summer. Additionally, a small number of homeowners refused inspections of their home and/or made their parcels inaccessible. Finally, Saint John's County experienced multiple mosquito outbreaks and two hurricanes during the 2016 2017 fiscal year which limited resources and manpower for urban mosquito control in downtown Saint Augustine. To circumvent these issues, new strategies that allow for rapid and thorough detection of container density should be developed.
The downtown Ae.aegypti surveillance project revealed that just over half the parcels in downtown Saint Augustine may function as breeding sites for Ae. aegypti, and a portion of them may function as major hot spots for Ae. aegypti activity. Despite the data compiled during this investigation, some questions remain unanswered. What is the most effective toolset available to mosquito control districts to effectively control $A e$. aegypti where parcel density is high? What factors led to the resurgence of Ae. aegypti in downtown Saint Augustine, and can this be prevented from occurring in the rest of Saint Johns County? New methodologies are currently under development to prevent further spread of $A e$. aegypti, such as lethal ovitraps, incompatible insect technique, and sterile insect technique. The coupling of new control methods with thorough surveillance strategies may make these new technologies more efficient for mosquito abatement and disease prevention.

\section{ACKNOWLEDGMENTS}

We thank M. Clark, M.K. Gaines, R. Weaver, C. Bibbs, and other AMCD employees for partial participation in this project, and the residents for allowing us to use their properties to conduct the surveillance.

\section{REFERENCES CITED}

Bibbs CS, Crosier JE, D'Amato JM, Gibson-Corrado J, Xue R-D. 2018. Bromeliad targeted foliar treatments with Aqualuer ${ }^{\circledR}$ 20-20 for hot spot mitigation using three hand sprayers against Aedes albopictus (Diptera: Culicidae). J Vector Ecol 43(2):215-219.

Braack L, Gouveia de Almeida AP, Cornel AJ, Swanepoel R, de Jager C. 2018. Mosquito-borne arboviruses of African origin: Review of key viruses and vectors. Parasit Vectors 11(1):29.

Centers for Disease Control and Prevention. 2017. Surveillance and control of Aedes aegypti and Aedes albopictus in the United States. https://www.cdc.gov/ zika/pdfs/Guidelines-for-Aedes-Surveillance-andInsecticide-Resistance-Testing.pdf. [accessed April 22, 2020].

Centers for Disease Control and Prevention. 2019. Zika virus statistics and maps. https://www.cdc.gov/zika/ reporting/index.html. [accessed April 22, 2020].

Christophers, RC. 1960. Aedes aegypti the yellow fever mosquito: Its life history, bionomics, and structure. Cambridge: Cambridge University Press.

Kaplan L, Kendell D, Robertson D, Livdahl T, Khatchikian C. 2010. Aedes aegypti and Aedes albopictus in 
Bermuda: Extinction, invasion, invasion and extinction. Biol Invasions 12(9):3277-3288.

Koppolu V, Shantha Raju T. 2018. Zika virus outbreak: A review of neurological complications, diagnosis, and treatment options. J Neurovirol 24(3):255-272.

Kotsakiozi P, Gloria-Soria A, Caccone A, Evans B, Schama R, Martins AJ, Powell JR. 2017. Tracking the return of Aedes aegypti to Brazil, the major vector of the dengue, chikungunya and Zika viruses. PLoS Negl Trop Dis 11(7):e0005653.

Liang S, Hapuarachchi H, Rajarethinam J, Koo C, Tang C, Chong C, Ng L, Yap G. 2018. Construction sites as an important driver of dengue transmission: Implications for disease control. Bmc Infect Dis 18:382

Lounibos L. 2007. Competitive displacement and reduction. J Am Mosq Control Assoc 23(2):276.

Lounibos LP, Kramer LD. 2016. Invasiveness of Aedes aegypti and Aedes albopictus and vectorial capacity for chikungunya virus. J Infect Dis 214(5):453-458.

Löwy I. 2017. Leaking containers: Success and failure in controlling the mosquito Aedes aegypti in Brazil. Am J Public Health 107(4):517-524.

Maciel-de-Freitas R, Marques WA, Peres RC, Cunha SP, Lourenço-de-Oliveira R. 2007. Variation in Aedes aegypti (Diptera: Culicidae) container productivity in a slum and a suburban district of Rio de Janeiro during dry and wet seasons. Memórias do Instituto Oswaldo Cruz 102(4):489-496.

Mead P, Duggal N, Hook S, Delorey M, Fischer M, McGuire D, Becksted H, Max R, Anishchenko M, Schwartz A, et al. 2018. Zika virus shedding in semen of symptomatic infected men. $N$ Engl J Med 378(15):1377-1385.

Mocellin MG, Simões TC, Nascimento TFSd, Teixeira MLF, Lounibos LP, Oliveira RLd. 2009. Bromeliadinhabiting mosquitoes in an urban botanical garden of dengue endemic Rio de Janeiro - are bromeliads productive habitats for the invasive vectors Aedes aegypti and Aedes albopictus? Memórias do Instituto Oswaldo Cruz 104:1171-1176.

Montgomery B, Ritchie S. 2002. Roof gutters: A key container for Aedes aegypti and Ochlerotatus notoscriptus (Diptera: Culicidae) in Australia. Am J Trop Med Hyg 67(3):244-246.

Muzari O, Adamczyk R, Davis J, Ritchie S, Devine G. 2014. Residual effectiveness of lambda-cyhalothrin harborage sprays against foliage-resting mosquitoes in North Queensland. J Med Entomol $51(2): 444-449$.
O’Meara G, Evans L, Gettman A, Cuda J. 1995. Spread of Aedes albopictus and decline of Aedes aegypti (Diptera, Culicidae) in Florida. J Med Entomol 32(4):554-562.

O’Meara G, Cutwa M, Evans L. 2003. Bromeliad-inhabiting mosquitoes in south Florida: Native and exotic plants differ in species composition. $J$ Vector Ecol 28(1):37-46.

Pittendrigh C. 1948. The bromeliad-anopheles-malaria complex in Trinidad .1. The bromeliad flora. Evolution 2(1):58.

Poland G, Ovsyannikova I, Kennedy R. 2019. Zika vaccine development: Current status. Mayo Clin Proc 94(12):2572-2586.

Reiter P. 2007. Oviposition, dispersal, and survival in Aedes aegypti: Implications for the efficacy of control strategies. Vector Borne Zoonotic Dis 7 (2):261-273.

Rey JR. 2014. Dengue in Florida (USA). Insects 5 (4):9911000.

Russell B, Muir L, Weinstein P, Kay B. 1996. Surveillance of the mosquito Aedes aegypti and its biocontrol with the copepod Mesocyclops aspericornis in Australian wells and gold mines. Med Vet Entomol 10 (2):155-160.

Santos C, Leite G, Falqueto A. 2011. Do native bromeliads represent important breeding sites for Aedes aegypti (L.) (Diptera: Culicidae) in urbanized areas? Neotrop entomol 40(2):278-281.

Unlu I, Faraji A, Indelicato N, Fonseca D. 2014. The hidden world of Asian tiger mosquitoes: Immature Aedes albopictus (Skuse) dominate in rainwater corrugated extension spouts. Trans $R$ Soc Trop Med Hyg 108(11):699-705.

Viennet E, Ritchie SA, Williams CR, Faddy HM, Harley D. 2016. Public health responses to and challenges for the control of dengue transmission in high-income countries: Four case studies. PLoS Negl Trop Dis 10(9):e0004943.

Wilke A, Vasquez C, Mauriello P, Beier J. 2018. Ornamental bromeliads of Miami-Dade County, Florida are important breeding sites for Aedes aegypti (Diptera: Culicidae). Parasit Vectors 11(1):283.

Wilke A, Chase C, Vasquez C, Carvajal A, Medina J, Petrie $\mathrm{W}$, Beier J. 2019. Urbanization creates diverse aquatic habitats for immature mosquitoes in urban areas. Sci Rep 9 .

Xue RD, Lippi C, Drake L. 2018. Species composition of mosquitoes and invertebrates in common bromeliad plant axils (family: Bromeliaceae) and the plant impacts on survival of vector mosquito Aedes albopictus (Diptera: Culicidae). Chin Trop Med 18(1): 6-10. 